\title{
UK Renal Registry 11th Annual Report (December 2008): Chapter 1 Summary of findings in the 2008 UK Renal Registry Report
}

\author{
David Ansell $^{a}$ \\ aUK Renal Registry, Bristol, UK
}

In 2007, all but one UK renal centre provided electronic data extracts to the UK Renal Registry. In the UK, the acceptance rate in 2007 was 109 per million population (pmp) compared to $111 \mathrm{pmp}$ in 2006. Acceptance rates in England (107 pmp), Scotland (108 pmp) and Northern Ireland (105 pmp) have fallen slightly, whilst that in Wales (140 pmp) has risen. The median age of all incident patients was $64.1 \mathrm{yrs}$ and for non-Whites $57.1 \mathrm{yrs}$. Diabetic renal disease remained the single most common cause of renal failure (21.9\%). By 90 days, $67.4 \%$ of patients were on $\mathrm{HD}, 21.3 \%$ on $\mathrm{PD}, 5.2 \%$ were transplanted and $6.1 \%$ had died or stopped treatment. The incidence of late presentation ( $<3$ months) was $21 \%$.

There were 45,484 adult patients receiving RRT on 31/ 12/2007. The population prevalence for adults was 746 per million population per year (pmp) with an annual increase in prevalence of approximately $5 \%$ per annum. The median age of prevalent RRT patients was $57 \mathrm{yrs}$ (HD 65 yrs, PD 60 yrs, transplant 50 yrs). Median RRT vintage was $5.3 \mathrm{yrs}$ (HD $2.8 \mathrm{yrs}, \mathrm{PD} 2.1 \mathrm{yrs}$, transplant $10.4 \mathrm{yrs})$. The prevalence rates for males peaked in the 75-79 year age band at 2,506 pmp and in females in the 70-74 year age band at $1,314 \mathrm{pmp}$. The most common treatment modality was transplantation (46.6\%), closely followed by centre-based HD (42.1\%) in either the primary centre $(25.2 \%)$ or the satellite unit $(16.9 \%)$. The HD population has continued to expand, and the PD population to contract.

Increasing live and non-heartbeating donors were responsible for the increasing transplant activity. Transplant waiting list numbers continued to rise by $8 \%$. Graft failure occurred in $3.2 \%$ of prevalent transplant patients. Death rates remained stable at 2.3/100 patient years. Malignancy accounted for $21 \%$ of these deaths. Analysis of prevalent transplants by CKD stage showed $16 \%$ with eGFR $<30$ and $2.2 \%<15$. Of those in stage $5 \mathrm{~T}, 26 \%$ had $\mathrm{Hb}<10 \mathrm{~g} / \mathrm{dl}, 27 \%$ phosphate $>1.8 \mathrm{mmol} /$ $\mathrm{L}$ and $50 \%$ an $\mathrm{iPTH}>32 \mathrm{pmol} / \mathrm{L}$. These patients were less likely to achieve the UK Standards in comparison to $\mathrm{CKD} 5$ dialysis patients.

In the incident RRT cohort, $52 \%$ had one or more comorbidities. Diabetes mellitus and ischaemic heart disease were the most common conditions seen in $28.9 \%$ and $22.5 \%$ of patients respectively. Comorbidities were more common in Whites and were associated with a greater likelihood of starting on HD (rather than PD). In multivariable survival analysis, malignancy and ischae$\mathrm{mic} /$ neuropathic ulcers were the strongest predictors of poor survival.

The 2006 unadjusted 1 year after 90 day survival for patients starting RRT was $86 \%$. In incident 18-64 year olds the unadjusted 1 year survival has risen from $85.9 \%$ in 1997 to $91.5 \%$ in 2006 and for those aged

\section{KARGER \\ Fax +4161306 1234 E-Mail karger@karger.ch} www.karger.com
(C) $2009 \mathrm{~S}$. Karger AG, Basel

$1160-2110 / 09 / 1115-0001 \$ 26.00 / 0$

Accessible online at: www.karger.com/nec
David Ansell

UK Renal Registry, Southmead Hospital, Southmead Road, Bristol BS10 5NB, UK

Email: renalreg@renalreg.com 
$>65$ it has risen from $63.8 \%$ to $72.9 \%$. The age adjusted survival of prevalent dialysis patients rose from $85 \%$ in 2000 to $89 \%$ in 2007. Diabetic patient survival rose from $76.6 \%$ in 2000 to $84.0 \%$ in 2007 . The relative risk of death on RRT compared with the general population was 30 at age 30 years compared with 3 at age 80 years. In the prevalent RRT dialysis population, cardiovascular disease accounted for 34\% of deaths, infection $20 \%$ and treatment withdrawal $14 \%$.

$81 \%$ of prevalent HD patients met the UK Clinical Practice Guideline for URR ( $>65 \%)$. This has increased from $56 \%$ in 1998 to $81 \%$ in 2007 .

This year for the first time there has been a small fall (from $85.9 \%$ in 2006 to $85.6 \%$ ) in the percentage of $\mathrm{HD}$ patients with a $\mathrm{Hb}$ of $>10 \mathrm{~g} / \mathrm{dl}$. This contrasts with previous annual improvements in this figure and is related to implementation of the new $\mathrm{Hb}$ Standard which has a target range of $10.5-12.5 \mathrm{~g} / \mathrm{dl}$. The median $\mathrm{Hb}$ in prevalent $\mathrm{HD}$ patients was $11.6 \mathrm{~g} / \mathrm{dl}$ with $86 \%$ having $\mathrm{Hb} \geqslant 10.0 \mathrm{~g} / \mathrm{dl}$. The median $\mathrm{Hb}$ on $\mathrm{PD}$ was $11.9 \mathrm{~g} / \mathrm{dl}$ with $91 \%$ having $\mathrm{Hb} \geqslant 10.0 \mathrm{~g} / \mathrm{dl}$. In $200758 \%$ of patients commenced RRT with $\mathrm{Hb} \geqslant 10.0 \mathrm{~g} / \mathrm{dl}$ (median $\mathrm{Hb} 10.3 \mathrm{~g} / \mathrm{dl}$ ). Of incident patients $81 \%$ and $87 \%$ had $\mathrm{Hb} \geqslant 10.0 \mathrm{~g} / \mathrm{dl}$ by 3 and 6 months of dialysis treatment respectively. The median ferritin in HD patients was $417 \mu \mathrm{g} / \mathrm{L}$ and $95 \%$ had a ferritin $\geqslant 100 \mu \mathrm{g} /$ L. The median ferritin in PD patients was $255 \mu \mathrm{g} / \mathrm{L}$ with $85 \%$ having a ferritin $\geqslant 100 \mu \mathrm{g} / \mathrm{L}$. The mean ESA dose was higher for HD than PD patients (9,300 vs. 6,100 IU/week).

Serum phosphate was between $1.1-1.8 \mathrm{mmol} / \mathrm{L}$ in $53 \%$ of HD and $64 \%$ of PD patients. Since 2003 there has been annual improvement in phosphate control for both HD and PD patients, largely through a reduction in phosphate $>1.8 \mathrm{mmol} / \mathrm{L}$. PD patients this year also showed a reduction in the percentage with a low phosphate. Adjusted calcium was between $2.2-2.6 \mathrm{mmol} / \mathrm{L}$ in $73 \%$ of $\mathrm{HD}$ and $78 \%$ of PD patients. Parathyroid hormone was between $16-32 \mathrm{pmol} / \mathrm{L}$ in $25 \%$ of $\mathrm{HD}$ and $27 \%$ of PD patients.

Significantly more haemodialysis patients achieved the BP standard (44.6\% pre-HD and $48.8 \%$ post-HD) than peritoneal dialysis $(32.8 \%)$ or renal transplant patients (26.7\%). Median BP fell significantly between 2000 and 2007 for each treatment modality. There was significant variability in BP control between renal centres $(\mathrm{p}<0.0001)$ for haemodialysis and transplant patients. Hypertension was significantly more common in haemodialysis patients with vascular disorders such as diabetes and renovascular disease $(56.8 \%)$ than in glomerulonephritis $(51.0 \%)$ or tubular disorders $(45.1 \%)$. The effect was less prominent in peritoneal dialysis and not evident in transplant patients where few achieve the BP standard.

From April 2007, all centres providing RRT in England were asked to provide additional data on patients with MRSA bacteraemia. From April 2007-March 2008, 188 discrete episodes of MRSA bacteraemia were reported in patients receiving dialysis. Over the same period 4,448 MRSA bacteraemias were reported in England, indicating that $4.2 \%$ of all cases occurred in dialysis patients. The relative risk of MRSA bacteraemia was about 8 fold higher for a patient using a catheter in comparison to a fistula. The mean rate using just HD patients as the denominator, was $1.14 \pm 0.95$ episodes/100 patients/year with a range of 0-3.93. Compared to previous registry reports, absolute numbers of reported MRSA bacteraemias has fallen by approximately $62 \%$ from 2004.

The UK paediatric RRT population in April 2008 was 875 patients with $74 \%$ transplanted. The proportion with grafts from living donors was $34 \%$. For those on dialysis, $57 \%$ were on PD. The prevalence under age 16 yrs was $55 \mathrm{pmp}$ and the incidence was $8 \mathrm{pmp}$. Children from ethnic minority groups were less likely to have an allograft and living donation was also less frequent. The rate of RRT for South Asians was 3 times that of the White and Black populations. Diseases with autosomal recessive inheritance were more common in patients from ethnic minority groups. Renal dysplasia was the most common diagnosis accounting for 33\% of prevalent RRT patients. The incidence of cystinosis causing ERF has fallen, reflecting better early treatment. Overall 5 year survival for children with ERF was $91.8 \%$. Five year survival of infants starting dialysis was just $62 \%$. 